\title{
Reconstrução e crítica imanente: Rahel Jaeggi e a recusa do método reconstrutivo na Teoria Crítica
}

\author{
Reconstrucion and immanent critique: Rahel Jaeggi and the \\ rejection of the reconstructive method in Critical Theory
}

\author{
Luiz Sérgio Repa \\ luizrepa@usp.br \\ (Universidade de São Paulo/CEBRAP, São Paulo, Brasil)
}

\begin{abstract}
Resumo: 0 objetivo principal do artigo consiste em discutir se o modelo habermasiano de crítica reconstrutiva é um tipo de crítica imanente. Para isso, procurase expor e rebater a posição de Rahel Jaeggi segundo a qual a crítica reconstrutiva é antes um tipo de crítica interna que tem um aspecto mais conservador do que transformador. Em vez disso, defende-se que a crítica reconstrutiva habermasiana apresenta traços específicos que configuram um tipo novo de crítica imanente, em comparação com a crítica da ideologia, um tipo mais ligado às práticas sociais e às regras estruturantes dessas práticas.
\end{abstract}

Palavras-chave: reconstrução; crítica imanente; Teoria Crítica; ideologia; emancipação.
Abstract: The main objective of this article is to discuss whether Habermas's model of reconstructive criticism is a kind of immanent critique. It tries to expose and refute the position of Rahel Jaeggi, according to which reconstructive criticism is rather a kind of internal critique that has a more conservative than transforming feature. Instead, it is argued that reconstructive criticism in Habermas presents specific traits that make up a new kind of immanent critique, compared to the critique of ideology, a kind that is more connected to structuring rules of social practices.

Keywords: reconstruction; immanent critique; Critical Theory; ideology; emancipation.

Entre os representantes da Teoria Crítica desde Jürgen Habermas, Rahel Jaeggi consta como uma das poucas posições contrárias à categoria de reconstrução no interior dessa corrente. Se Habermas introduziu essa categoria no final dos anos sessenta e a desenvolveu de modos diferentes, ${ }^{1}$ se Axel Honneth a generaliza como método da Teoria Crítica, desdobrando concepções diferenciadas de "reconstrução normativa" e "crítica reconstrutiva" em sua obra mais recente, ${ }^{2}$ se Mattias Iser (2013) procura formular uma noção própria de reconstrução reunindo as de Habermas e

1 Cf. Habermas, 2014; 1989; 1984; 1976; 1987; 1992. Sobre o método da reconstrução em Habermas, cf. Pedersen, 2008; Iser, 2009; Repa, 2008a; Nobre, Repa, 2012.

2 Cf. Honneth, 2007; 2010; 2011. Sobre a concepção honnethiana de reconstrução, cf. Nobre, 2013. 
Honneth, se, enfim, Robin Celikates procura retomar e levar adiante uma determinada concepção habermasiana de reconstrução, em detrimento de outras (cf. Celikates, 2009; 2012) - se, portanto, todos esses nomes articulam seus modelos de Teoria Crítica segundo a ideia de reconstrução, ${ }^{3}$ Jaeggi se destaca, em sentido inverso, por recusar a adequação dela à tradição da Teoria Crítica.

De acordo com a apreciação de Jaeggi, a crítica reconstrutiva poderia ter características até mesmo opostas àquelas que se espera de uma Teoria Crítica da sociedade, uma vez que a reconstrução se confundiria com a "restauração de uma ordem existente e restabelecimento de normas e ideais vigentes" (Jaeggi, 2014, p.295; cf. idem, 2008). Em vez disso, Jaeggi busca resgatar uma concepção de crítica imanente, inscrita em Hegel, Marx e Freud, a qual ela trata de contrapor à crítica reconstrutiva: "a crítica imanente é menos dirigida à reconstrução ou ao resgate [Einlösung] de potenciais normativos do que a uma transformação do existente, promovida por problemas e contradições imanentes de uma determinada constelação social" (idem, 2014, p.277; cf. idem, 2008, p.155).

Embora Jaeggi tenha como referência, sobretudo, a compreensão de Honneth a respeito da crítica reconstrutiva, é evidente que ela pretende estabelecer uma via metodológica diferenciada no interior da Teoria Crítica mais recente. A questão que proponho examinar aqui consiste em saber até que ponto se justifica a separação entre a ideia de crítica imanente e o método reconstrutivo, e isso em Habermas, o inaugurador de uma "virada reconstrutiva" na Teoria Crítica, para se valer da expressão de Olivier Voirol. Depois de uma rápida visão sobre como Honneth generaliza a noção de reconstrutiva, vou abordar as características da crítica imanente, tal como esboçadas por Jaeggi, para enfim contrapô-las ao conceito habermasiano de reconstrução, tal como ele se desenvolve nos anos 1970 e $1980 .{ }^{4}$ Nesse passo, defendo a hipótese de que, apesar de algumas diferenças importantes em relação à crítica imanente, tal como Jaeggi a defende, a noção habermasiana de reconstrução pode se inserir nesse gênero de crítica. Isso significa que não ocorre um abandono da ideia de potenciais de transformação, necessários para satisfazer de alguma maneira o interesse por formas de vida emancipadas. ${ }^{5}$

3 Para uma visão de conjunto sobre a reconstrução como método privilegiado da Teoria Crítica contemporânea, cf. Strydom, 2011; cf. também Voirol, 2012.

4 Deixarei de lado, portanto, outras concepções de reconstrução em Habermas, como podem se articular em Conhecimento e interesse e Facticidade e validade.

5 Sobre o interesse por um estado racional, emancipado, como traço característico da Teoria Crítica, cf. o texto seminal de Max Horkheimer, "Teoria Tradicional e Teoria Crítica". Cf. Horkheimer, 1975. Sobre isso, cf. Nobre, 2004. 
Reconstrução e crítica imanente: Rahel Jaeggi e a recusa do método reconstrutivo...

O traço característico da reconstrução, como categoria central da Teoria Crítica habermasiana, ${ }^{6}$ reside na ideia de que há uma racionalidade existente, no interior de um sistema de construções e práticas simbólicas e sociais, a qual não pode ser descartada na medida em que estrutura princípios elementares desse sistema. A reconstrução recupera, assim, na reprodução da sociedade como um todo, os elementos de uma racionalidade existente, porém insuficientemente explorada e capaz de exercer pressão sobre a realidade dada. Se com cada enunciado se antecipam os pressupostos de uma discussão livre de coerção, então a cada uso da linguagem, mesmo em comunicações sistematicamente distorcidas, essas condições como que forçam para além do que vige factualmente:

(...) as estruturas mais universais da comunicação que os sujeitos capazes de falar e agir aprenderam a dominar não abrem apenas o acesso a determinados contextos; elas não possibilitam apenas a ligação com e a continuação de contextos que, como pareceria de início, atraem os participantes à jurisdição do meramente particular. Essas mesmas estruturas oferecem ao mesmo tempo os meios críticos para penetrar um contexto dado, para explodi-lo e transcendê-lo a partir de dentro, para, se necessário, enfrentar de ponta a ponta um consenso factualmente estabelecido. (Habermas, 1987, p.176)

Ora, se é assim, a ideia de reconstrução se alia imediatamente com o princípio da Teoria Crítica, uma vez que lhe é inerente a direção do interesse pela emancipação no sentido da descoberta de potenciais imanentes de negação de práticas coercitivas. Para Mattias Iser, é possível falar então de uma "crítica reconstrutiva da sociedade", de acordo com a qual "a razão prática não se esgotaria em um mero dever, mas seria já operante no interior da realidade social” (Iser, 2009, p.366; cf. idem, 2008, p.10).

No entanto, a expressão “crítica reconstrutiva da sociedade” não é de origem habermasiana. Ela foi criada por Axel Honneth para simplesmente caracterizar a totalidade da Teoria Crítica “clássica”, incluindo aí o próprio Habermas. No seu pequeno ensaio de 2007 sobre "Crítica reconstrutiva da sociedade sob a reserva genealógica - sobre a ideia de 'crítica' na Escola de Frankfurt”, Honneth pretende fazer uma defesa, ainda que relativamente distanciada quanto aos aspectos mais materiais, do “modelo clássico de crítica” empreendido por seus antecessores do Instituto de Pesquisa Social. Trata-se aí não de uma reconstituição da implementação desse modelo clássico em todos os escritos correspondentes, mas de uma "forma ideal".

Para tanto, Honneth parte da conhecida tipologia proposta por Michael Walzer no livro Interpretation and Social Criticism, segundo a qual haveria três formas

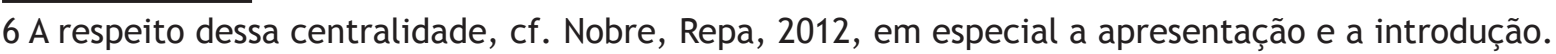


fundamentais de crítica social, diferenciadas entre si pelo modo como se chega às normas e aos princípios subjacentes, ou seja, pelos procedimentos da "revelação", da "invenção" e da "interpretação". Deixando de lado a primeira referência, de caráter metafísico ou religioso, Honneth propõe mudanças terminológicas para as outras duas: "construção" para invenção, pois se trata aí de métodos "construtivistas", e "reconstrução" para interpretação, pois, apesar do maior acento no aspecto hermenêutico, trata-se aí de algo que o próprio Marx realizara a título de crítica imanente da ideologia, ou seja, de buscar na própria realidade o princípio de sua crítica.

Uma vez que Honneth reinterpreta a crítica imanente em Marx já como uma forma de "crítica reconstrutiva", não é difícil para ele alastrar essa noção à Teoria Crítica clássica, de modo que "Horkheimer, Adorno e Marcuse se empenharam até certo momento por uma via reconstrutiva de fundamentação de sua crítica social" (Honneth, 2007, p.64), de modo que a teoria reconstrutiva de Habermas aparece apenas como uma continuidade dessa via. As diferenças começam pelo modo como os critérios normativos, imanentes à sociedade criticada, podem se justificar, pois a Teoria Crítica não lida só com uma normatividade factual, mas com uma normatividade justificável.

A estratégia metodológica tácita de Honneth parece consistir na substituição da "dialética", como categoria capaz de abranger as diferentes versões ou modelos de Teoria Crítica, por uma categoria capaz de integrar não só Habermas e ele próprio. Com isso, ele contribui para um "paradigma da reconstrução" no interior da Teoria Crítica, como sugere Olivier Voirol:

Seja na forma de uma "reconstrução normativa" (Honneth), seja na de uma "reconstrução racional" (Habermas), a reconstrução se tornou o método da Teoria Crítica desde a "virada reconstrutiva". Como já foi dito, a reconstrução também transformou as articulações entre filosofia e ciência, entre teoria e pesquisa, entre fundação normativa e investigação científica, quando comparadas com o modelo dialético do primeiro Horkheimer. (Voirol, 2012, p.95)

Porém, a generalização de Honneth faz que a categoria de reconstrução abranja a Teoria Crítica clássica e, assim, autores tão distintos como Adorno, Horkheimer, Marcuse e Habermas (e o próprio Honneth). Essa generalização fortalece em todo caso a tendência de ver na reconstrução o paradigma metodológico mais adequado para satisfazer os princípios da teoria crítica, como é a visão de P. Strydom:

Para os objetivos mais particulares da produção de conhecimento praticamente relevante, os teóricos críticos contemporâneos operam com outro conceito correlato [ao de transcendência imanente], o qual se tornou central para a autocompreensão metodológica da Teoria Crítica - a saber: reconstrução. (...) As implicações metodológicas da transcendência imanente são decifradas da melhor maneira quando se mantém em mente o conceito de reconstrução. (Strydom, 2011, p.135) 
Contudo, não é essa a posição metodológica de Rahel Jaeggi. Segundo sua tipologia das formas de crítica social, a crítica reconstrutiva é vista como uma crítica interna, que precisa ser diferenciada da crítica imanente, uma vez que esta se caracteriza por trazer consigo a consideração sistemática da transformação social. Ora, tal distinção entre crítica interna e crítica imanente, realizada no eixo da transformação realmente possível, afeta também a compreensão de como uma teoria pode ser considerada teoria crítica.

Segundo Jaeggi, a crítica interna se distingue de todo tipo de crítica externa porque procura situar os seus critérios normativos no objeto criticado. Ao contrário, portanto, da crítica externa, que, seja de maneira transcendental, seja de maneira antropológica, parte de um princípio construtivista que pode coincidir com o âmbito do que é criticado, mas por natureza tem de situar-se exteriormente ou por exigência teórica precisa operar um distanciamento metodológico em relação ao objeto, a crítica interna pretende se colocar como que no seu interior. 0 que é crítico nessa forma de crítica interna é a constatação de um descompasso entre a autocompreensão daqueles que constituem o âmbito investigado e a realização do conteúdo dessa autocomprensão:

Crítica interna é uma forma de crítica (...) que parte de que determinados ideais e normas pertencem, sem dúvida, à autocompreensão de uma determinada comunidade, mas de fato não são realizados nela. A "efetividade" de determinadas práticas e instituições é medida, então por esses ideais já contidos nela mas não realizados. (Jaeggi, 2014, p.263)

O que os diversos casos de crítica interna apontam, conforme a autora, é uma inconsistência, um desacordo ou uma contradição interior entre os componentes normativos, ostensivamente aceitos nos grupos criticados, e a realidade factual praticada em geral no interior deles. Aquele que não realiza o que afirma é criticado justamente pelos critérios que defende abertamente. Mas, se é assim, o empreendimento da crítica interna tende a ser conservadora: ela busca reafirmar os componentes normativos defendidos por quem não os realiza de uma maneira ou de outra. Trata-se, então, de uma "restituição de princípios" ou da "reativação do sentido verdadeiro" de alguns ideais - em todo caso, não se coloca a perspectiva de uma transformação dos princípios pelos quais a crítica se guia. O que implica, por sua vez, uma aceitação desses princípios como não dinâmicos. Soma-se a isso a pouca ou quase nenhuma distância normativa que a crítica interna pressupõe. De maneira geral, os princípios e ideais normativos não carecem de um processo de legitimação, e nesse sentido a crítica interna caminha para um modo de convencionalismo 
normativo, e, por consequência, uma vez que se trata de um conjunto de convenções dadas em determinado contexto, se apresenta também como particularista, como é o caso exemplar dos patriotismos que lamentam a decadência dos valores da pátria.

Juntamente com esse convencionalismo, essa forma de crítica tende a subestimar a importância dos processos de interpretação sobre as normas e as práticas que se distanciaram delas. Em muitos casos, a contradição não se revela de maneira patente, como no caso de uma incoerência literal. Apontar uma incoerência entre práticas e normas pode significar a ignorância sobre o modo como essas práticas contraditórias se interpretam ou sobre a multiplicidade de referências normativas existentes em uma sociedade. Ou seja, a crítica interna tende a recusar os potenciais de conflito envolvidos nas necessidades de interpretações em situações complexas, pressupondo com isso uma certa homogeneidade social.

Como último traço problemático, Jaeggi acentua a impossibilidade, no interior de sociedades plurais, de determinar até que ponto a crítica procede de "fora" ou de "dentro". Como valores diferentes são partilhados no interior de uma mesma sociedade, os limites da exterioridade ou interioridade normativa não podem ser bem definidos.

Embora Jaeggi tenha em vista aqui, sobretudo, a concepção de "interpretação" de Michael Walzer, como vimos acima a partir das considerações de Honneth, na qualidade de crítica social interna, é chamativo que ela denomine "reconstrutivo" o caráter geral desse tipo, ao passo que a forma da crítica imanente seria "transformativa". Certamente, a formulação pretende atingir em primeiro lugar a concepção honnethiana de crítica reconstrutiva, na versão geral que apresentamos acima. Mas por isso mesmo são evidentes também suas consequências para a compreensão habermasiana, seja como caso exemplar de método reconstrutivo, seja como ponto de partida efetivo da compreensão honnethiana. Se em diversos aspectos a descrição feita da crítica interna está longe de acertar o alvo no caso de Habermas (como também no caso de Honneth), o problema maior apontado por Jaeggi se impõe: uma tarefa reconstrutiva de potencialidades não realizadas não se resume a uma crítica interna que simplesmente reitera seu sentido normativo? A crítica reconstrutiva, enquanto crítica interna, não se resumiria afinal em uma comparação entre potencial e efetividade? E assim a crítica reconstrutiva não seria estática, não inovadora, e, o que é mais importante, não escaparia à intenção e às categorias que explicam como se pode contar com uma transformação da sociedade em função das potencialidades reconstruídas? Se tivermos de concordar com essa tipologia, a unidade entre reconstrução e crítica evidentemente se debilita.

Jaeggi estabelece como próprio da sua concepção de crítica imanente, apoiada em Hegel, em Marx e na psicanálise, o "nexo íntimo entre análise e crítica": 
Reconstrução e crítica imanente: Rahel Jaeggi e a recusa do método reconstrutivo...

Nisso, a análise não é apenas uma pré-condição instrumental para a crítica, mas o componente do próprio processo crítico. Ela é crítica enquanto análise (e não uma mera descrição do existente) e é análise enquanto crítica (e não uma mera exigência feita ao existente). (Jaeggi, 2014, p.280)

Portanto, não haveria aqui, no caso da crítica imanente, uma hierarquia lógica e temporal entre teoria e crítica.

Tampouco haveria uma reafirmação do que é tomado como critério normativo. Como é o caso da primeira concepção de crítica imanente, formulada pela primeira vez na Introdução da Fenomenologia do espírito, o critério é, certamente, interno ao objeto, ou seja, a cada figura da consciência na série em desenvolvimento da consciência. Mas, na medida em que cada figura da consciência se envolve na contradição entre o que ela estabelece como critério e seu saber ou prática efetiva, ela é transcendida a partir de dentro para fora de si mesma, isto é, para uma outra forma, que é, segundo o termo hegeliano, sua "negação determinada”, o “nada daquilo de que resulta" (Hegel, 2008, p.76).

Portanto, segundo esse modelo de crítica imanente, é preciso destacar, diferentemente do modelo geral da suposta crítica interna reconstrutiva, que o objeto é analisado em seu aspecto dinâmico e transformativo, por meio de contradições imanentes a ele. A mesma linha de raciocínio é aplicada à crítica da ideologia em Marx, como segundo caso paradigmático de crítica imanente. Nesse âmbito, é chamativo, segundo a autora, que Marx não se valha somente de uma mera comparação entre o que é normativamente afirmado nas ideologias burguesas, como a liberdade e a igualdade, e a realidade de não-liberdade e desigualdade sociais produzidas pela sociedade capitalista. Mais importante seria a demonstração do funcionamento ideológico desses princípios, uma vez que eles se tornam mecanismos de produção do seu oposto, por exemplo, pelo contrato de trabalho que levaria à exploração ao mesmo tempo em que segue as características formais da concepção burguesa:

Vê-se agora em que medida a crítica imanente justamente não segue o modelo de argumentação típico para a crítica interna (hermenêutico-reconstrutiva), de que uma comunidade tenha perdido a ligação com seus ideais. Pois ela não considera a relação entre normas e realidade na situação por ela criticada como dissolvida ou enfraquecida, mas como invertida ou equívoca em si. Isto é (tal como no caso acima referido, dos valores constitutivos da sociedade burguesa, liberdade e igualdade), as normas são eficazes, mas, como eficazes, elas tornaram-se contraditórias e deficitárias. (Jaeggi, 2008, p.156)

Não se trata de um descompasso entre norma e efetividade apenas, mas também do modo específico pelo qual a norma se torna eficaz e com isso contraditória, pois não produz liberdade ou igualdade alguma.

O terceiro caso paradigmático de crítica imanente seria o da psicanálise, 
mais precisamente, o diálogo psicanalítico, no qual a crítica se apresenta na forma de uma dissolução de autoenganos que parte dos próprios sintomas do paciente. Para Jaeggi, o diálogo psicanalítico comporta vários traços do processo dialético da Fenomenologia do espírito, na forma de uma relação recíproca entre a interpretação do analista e a autointerpretação do paciente (cf. Jaeggi, 2014, p.286) ${ }^{7}$.

Tendo esses casos como referência, Jaeggi atribui sete características à crítica imanente. Trata-se aí, primeiramente, da "normatividade do efetivo [Wirkliches]", a qual não se resume a valores e ideais explícitos, mas leva em conta uma normatividade constitutiva das práticas sociais; em segundo lugar, do "caráter constitutivo (-funcional) das normas" ao qual se atém a crítica: elas devem ser constitutivas do funcionamento da sociedade e também da autocompreensão dos participantes dela, como é o caso da igualdade e da liberdade de todos os indivíduos na sociedade burguesa, segundo o exemplo de Marx, e nesse aspecto as normas em questão não se apresentam de maneira factual, mas antes têm um caráter de "fundamentadas, racionais"; em terceiro lugar, da mencionada "eficácia invertida das normas", que se tornam contraditórias e “deficitárias" em razão de sua efetividade, porque se opõe ao “conteúdo das normas". Em consequência do caráter contraditório das práticas sociais diagnosticadas, é preciso sublinhar, em quarto lugar, "a orientação da crítica imanente pela crise", pela instabilidade, deficiência, disfuncionalidade, que estruturalmente põe sob ameaça a identidade de uma formação social. Em quinto lugar, destaca-se a "contraditoriedade paralela de efetividade e normas", com o que a crítica imanente se diferencia da interna porque não deixa intocadas as normas como padrão de medida fixo. Não se trata, assim, de atentar apenas para a efetividade da norma, mas também para a "norma na efetividade”. Consequentemente, o “critério da crítica se alterna no processo da crítica” (Jaeggi, 2014, p.293), como é o caso da crítica da liberdade e da igualdade como ideologia burguesa, que, se é primeiramente critério em oposição à realidade que nega a liberdade e a igualdade, precisa dar lugar a uma concepção positiva de liberdade e material de igualdade. Não se tem em vista assim a "efetivação do que está inscrito em um sentido estático", mas o próprio potencial a ser resgatado sofre também uma transformação no curso do resgate. A sexta característica foi enfatizada desde o início; mas agora é importante salientar também que a distinção entre transformação e reconstrução seria, para a autora, a "diferença mais marcante” entre a crítica imanente e a crítica interna. Por fim, como sétimo traço distintivo, menciona-se a ideia de "crítica imanente como processo de experiência e aprendizado", uma vez que a experiência de contradição

\footnotetext{
7 Nesse ponto, há uma convergência entre ela e a interpretação que Habermas faz da psicanálise em Conhecimento $e$ interesse, obra que não só nesse aspecto se assemelha às exigências postas por ela quanto à crítica imanente. Mas nos limitamos aqui, como antecipado de início, ao conceito de reconstrução no âmbito da Teoria da ação comunicativa. Sobre o papel da crítica imanente em Conhecimento e interesse, cf. Repa, 2008a.
} 
Reconstrução e crítica imanente: Rahel Jaeggi e a recusa do método reconstrutivo...

e de fracasso de uma formação social traz consigo o discernimento não só de uma posição falsa, mas também, junto com isso, uma nova posição, em consonância com a noção hegeliana de negação determinada.

Deixando de lado a natureza dessa concepção de crítica imanente, cujo caráter instigante parece evidente, cabe retomar a questão inicial e perguntar se, de fato, a crítica reconstrutiva se reduz à ideia de uma contraposição entre o normativo e o factual, abandonando o aspecto efetivamente transformador dos potenciais de racionalidade. Não por acaso, comecei a apresentando a noção de reconstrução em Habermas já conferindo ênfase a esse último aspecto. Assim, a crítica reconstrutiva não seria também uma forma específica de crítica imanente. Ao se voltar a essa questão, Titus Stahl não titubeia ao dizer que "compreendemos o projeto da Teoria da ação comunicativa como o desenvolvimento de um modelo de crítica imanente", o qual "pertence claramente ao campo da crítica baseada em práticas” (Stahl, 2013, p.537).

Com essa última expressão, Stahl pretende fazer uma diferenciação entre duas formas de crítica imanente, uma que busca seus critérios de orientação nas compreensões normativas partilhadas pelos atores sociais, na tentativa de realizar reinterpretações inovadoras. Esse modelo hermenêutico de crítica imanente é diferenciado daquele tipo de crítica imanente que não se atém às compreensões do atores, mas antes às suas práticas. Nesse aspecto, Habermas representaria, de fato, um desdobramento do modelo de crítica proveniente de Marx. Ao mesmo tempo, esta já é descrita em termos habermasianos:

Teóricos críticos marxistas e pós-marxistas frequentemente pretendem que eles estão engajados na forma da "crítica reconstrutiva" ou "imanente", isto é, (...) uma forma de crítica que objetiva empregar potenciais normativos, tais como os potenciais para a nova sociedade contidos nas práticas de solidariedade dos trabalhadores ou na experiência partilhada de opressão. Esses potenciais transcendem as normas consentidas de uma sociedade, mas são, de uma maneira ou de outra, já “imanentes" na realidade social. (Stahl, 2013, p.534)

A distinção entre uma forma hermenêutica de crítica imanente, relativamente próxima do que acima foi designado de crítica interna, e a forma própria imanente, reconstrutiva, serve ao comentador para relativizar o distanciamento de Habermas em relação ao recurso da imanência normativa. Stahl se refere aqui às conhecidas objeções que Habermas levanta contra uma crítica imanente da ideologia na medida em que predomina o cinismo na consciência dos destinatários da crítica. Uma passagem conhecida é a seguinte, tirada de Para a reconstrução do materialismo 


\section{histórico:}

A falta de clareza imperou desde o início sobre os fundamentos normativos da teoria social de Marx. (...) Ele pôde se contentar em tomar ao pé da letra e criticar de modo imanente o conteúdo normativo das teorias burguesas dominantes, do direito natural moderno e da Economia Política (o qual, além disso, havia sido incorporado nas constituições burguesas revolucionárias). Entretanto, a consciência burguesa se tornou cínica: ela foi completamente esvaziada de conteúdos normativos vinculantes, como mostram as ciências sociais, em especial o positivismo jurídico, o neoclassicismo das ciências econômicas e a nova teoria política. Mas se os ideais burgueses são suprimidos, como se apercebe de forma cada vez mais flagrante em tempos de recessão, faltam normas e valores aos quais uma crítica que procede de maneira imanente poderia apelar com concordância. (Habermas, 1976, pp.10-11)

Para Stahl, uma semelhante passagem mostraria que o cinismo, a afirmação nua e crua de dominação, de exclusão, de subjugação, de desigualdade e de coerção afetaria unicamente a forma hermenêutica de crítica imanente, porque ela se ateria às compreensões normativas dos atores sociais, no caso, à consciência burguesa na qualidade de padrão cultural dominante. Por sua vez, Jaeggi considera que esse tipo de problema apontado por Habermas afetaria tão somente a crítica interna: “em uma sociedade sem ideais ou em uma sociedade que tivesse se convertido ao cinismo, a crítica interna não encontraria de certa maneira nenhum suporte” (Jaeggi, 2014, p.273).

Porém, as coisas não se passam de maneira tão simples em uma ótica habermasiana. Na concepção proposta por Jaeggi, é digno de nota que, se os valores e normas que servem de objeto e apoio para a crítica não podem ser arbitrários, meramente convencionais, deve haver uma instância de racionalidade normativa: "as normas não dadas de maneira meramente fática, mas são consideradas como fundamentadas, como racionais" (Jaeggi, 2014, p.290; cf. idem, 2008, p.155). Além disso, segundo ela, a crítica imanente se liga também a um processo de aprendizagem que representa uma forma de progresso. Se, porém, não é possível contar com um mínimo de racionalidade, como prevê a hipótese de uma sociedade completamente cínica, também a crítica imanente, como Jaeggi a projeta, enfrenta dificuldades. A dependência em relação ao objeto não é de todo afastada quando se mantém distância em relação às autocompreensões e aos valores dos envolvidos. Enquanto imanente, a crítica tem de apelar a um núcleo de racionalidade - a forma da contradição dialética não é uma maneira de contornar essa exigência, é uma forma de explicitar a necessidade desse núcleo. Por isso, para Habermas, o problema do cinismo coloca uma exigência de fundamentação normativa dos critérios da crítica que não existia antes, para Marx. É justamente esse papel que Habermas confia às reconstruções racionais. A ética do discurso vai se compreender como um projeto de teoria moral inscrita no círculo das ciências reconstrutivas, capazes de fundamentar os critérios 
pelos quais se podem medir avanços ou retrocessos normativos. De modo geral, portanto, pode-se dizer que a identificação da debilidade da crítica imanente vai de par, em Habermas, com a urgência de uma tarefa de fundamentação normativa.

Porém, isso não significa recusar a estratégia mais geral de crítica imanente, mas sim os contornos específicos de uma forma determinada, aquela da crítica imanente da ideologia. Desse modo, Stahl não erra ao dizer que Habermas desenvolve sua abordagem no interior de um modelo de crítica imanente mais ligado às práticas do que às ideias e às autocompreensões imediatas dos autores.

Mas cabe perguntar ainda: esse modelo de crítica imanente, mais ligado às práticas, ou melhor dizendo, mais ligado às regras e às estruturas subjacentes às práticas sociais, pode cumprir as exigências de uma noção mais rigorosa de crítica imanente, como aquela defendida por Jaeggi?

Se podemos sustentar agora, contra Jaeggi, que há um tipo de crítica imanente que pode ser chamada de reconstrutiva, como também o quer Stahl, então o passo natural a ser dado é verificar até que ponto as exigências da crítica imanente, como formuladas por Jaeggi, podem ser cumpridas por Habermas na constelação da teoria da ação comunicativa.

Com isso, podemos realizar uma comparação da crítica reconstrutiva com aquela noção de crítica imanente defendida por Jaeggi, a qual se esforça por estabelecer o vínculo com a ideia constitutiva de transformação, que tem de ser inerente à Teoria Crítica enquanto tal. Certamente, é preciso enfatizar desde o início que Habermas confere à sua concepção de crítica reconstrutiva enquanto crítica imanente uma configuração pouco usual: o diagnóstico de modernidade proposto na Teoria da ação comunicativa se reporta a uma noção kantiana de crítica, de tal modo que o princípio normativo fundamental se baseia na ideia de que os âmbitos de racionalidade possuem legalidades próprias, que garantem sua autonomia e pleno desenvolvimento. Esse princípio está na base do juízo segundo o qual, ao longo da modernização capitalista, os sistemas dinheiro e poder conduzem um processo seletivo de potenciais de racionalidade já disponíveis com a racionalização cultural. As patologias sociais se explicariam então pelo fato de que dimensões importantes da racionalidade comunicativa estariam sofrendo um sufocamento por conta da invasão sistemicamente induzida da racionalidade cognitivo-instrumental (cf. Kneer, 1990).

É importante observar, quanto a esse último ponto, que tal predomínio não significasimplesmenteaeliminação das dimensõesprático-moral ouestético-expressiva da razão. Nesse contexto, Habermas fala de marginalização e enfraquecimento dessas dimensões, as quais são, ainda assim, constitutivas da práxis comunicativa cotidiana. 
Mas essa imagem não se reduz a uma simples forma de recalque, na acepção literal de impedir a manifestação. Muitas vezes ela se apresenta como um encurtamento do prático-moral ou do estético-expressivo no interior dessas dimensões, por exemplo, em concepções morais que assimilam pretensões de verdade teórica e pretensões de correção normativa. Nesses casos, talvez pudéssemos pensar na possibilidade de uma aplicação da crítica imanente a partir do princípio dominante; mas em geral, nesses campos, Habermas sempre parte da constatação da falta de alcance, e não tanto sobre a contradição interna do princípio. Ou seja, de modo geral, é o antagonismo entre dimensões de razão e não as contradições internas de um princípio de unificação o ponto de partida.

Assim, se retomarmos as exigências estabelecidas por Jaeggi, salta à vista que o princípio da "normatividade do efetivo" seria, tal como antes, uma própria condição da imanência da crítica, porém o efetivo inscrito na linguagem ganha um caráter menos concreto. Isso porque, na segunda exigência, o "caráter constitutivo e funcional das normas" não tem necessariamente uma configuração institucional. Mais problemática nessa comparação, porém, é a "eficácia invertida das normas". Não faz sentido falar que as estruturas constitutivas da racionalidade comunicativa teriam uma eficácia invertida porque o ponto de ancoragem da crítica é aquilo que foi reprimido. Por sua vez, "a orientação pela crise" continua a ser constitutiva, já que se trata para Habermas sempre de partir dos fenômenos patológicos das sociedades do capitalismo tardio. A "contraditoriedade paralela de efetividade e normas" tem um papel menor já que, novamente, não se trata de partir de contradições internas às normas. Trata-se antes, nesse contexto, de tentar fundamentar os princípios normativos da crítica à luz de uma efetividade antagônica e ao mesmo tempo ancorar esses princípios nas diversas dimensões dessa realidade. A sétima característica, "a crítica imanente como processo de aprendizado" tem um paralelo muito próximo com a ideia habermasiana de reconstrução vertical de processos de aprendizado, um aspecto que não pode ser desenvolvido aqui (cf. Repa, 2008; Bannwart, 2012).

Essas diferenças demonstram a especificidade da versão de crítica imanente com que Habermas tem de lidar no âmbito da Teoria da ação comunicativa. ${ }^{8}$ No entanto, a sexta característica, a respeito do caráter transformador da crítica imanente, é, na realidade, o que mais importa. Mas a crítica tem muito pouco a fazer se ela não puder também contar com movimentos sociais mais ou menos ativos na esfera pública. Para Habermas, os chamados novos movimentos sociais são reações às patologias do mundo da vida. Porém, a relação entre reconstrução e esfera pública, e de modo geral, a teoria política habermasiana, abriria um novo campo de discussão. Para o contexto da presente discussão, importa antes a estrutura lógica da crítica

8 Vale insistir que, com isso, não ignoramos a concepção de crítica imanente no âmbito de Conhecimento e interesse. 
Reconstrução e crítica imanente: Rahel Jaeggi e a recusa do método reconstrutivo...

reconstrutiva, mais especificamente, a relação entre reconstrução e transformação.

Do ponto de vista da crítica que Jaeggi estabelece contra a reconstrução, poder-se-ia dizer que aqui ainda residiria o ponto decisivo, pois Habermas se valeria de potenciais de racionalidade já disponíveis que não teriam sido ainda implementados na realidade. 0 ponto de ancoragem não seria as normas dominantes, é verdade, mas o modo de funcionamento da crítica ainda seria aquela da crítica interna que mede a efetividade pelas potencialidades e, como isso, não traz nada de novo.

Há dois aspectos a serem considerados aqui nessa questão: em primeiro lugar, a capacidade de realização desses potenciais de racionalidade, na medida em que eles precisam se engatar na efetividade. Em segundo lugar, o que significa dizer, no contexto da Teoria da ação comunicativa, que esses potenciais estão disponíveis?

A resposta a essa questão segundo esses dois aspectos nos leva a fechar finalmente o desenho da concepção de crítica reconstrutiva na Teoria da ação comunicativa. Nessa concepção, delineia-se não só um tipo de crítica imanente desvinculada das ideologias e remetidas às estruturas subjacentes às práticas cotidianas, não só um tipo de crítica imanente que incorpora uma noção kantiana de crítica; ela ainda tem de supor uma relação pouco comum de potencialidade e efetividade. Pois, se as patologias sociais surgem por repressão do desenvolvimento de todas as potencialidades da racionalidade comunicativa, é evidente então que não se trata de meras possibilidades, mas de algo que mostra sua efetividade por negação. Isso significa dizer que as potencialidades da racionalidade comunicativa não são apenas reais na acepção dada a esse termo na tradição dialética. Como elas são condições constitutivas de toda interação social mediada pela linguagem, é preciso atribuir a elas um tipo de efetividade que se evidencia por negação, cujo efeito fenomênico é, em grande escala, a patologia. Tudo isso torna claro que não se trata aqui de meras possibilidades não realizadas e nem mesmo de uma possibilidade cuja efetivação é garantida, mas de uma possibilidade que em um certo nível já é efetiva.

No entanto, de modo algum Habermas ancora sua crítica às sociedades capitalistas apenas nesse tipo de possibilidades inscritas na comunicação com suas condições. Antes, esse raciocínio só ganha plausibilidade se for possível mostrar que os processos discursivos são ao mesmo tempo demandados e recortados com a racionalização e a modernização capitalista. Mas Habermas está longe de dizer que formas determinada surgirão do aproveitamento dos recursos já disponíveis no solo da modernidade cultural. Um tratamento não objetificado consigo mesmo e com os parceiros da interação pode se configurar concretamente de diversas formas, de modo que o efeito transformador, vale dizer, o efeito emancipatório dessa concretização de algo que estava sempre lá, mas não de uma maneira precisa, não é mensurável de antemão. Desse modo, não se trata de uma crítica interna que contrapõe norma 
e efetividade, possibilidade e realidade. A crítica reconstrutiva aponta antes para as condições de possibilidade da comunicação, que são imanentes às práticas dadas e capazes de apresentar múltiplas formas de constituição histórica.

\section{Referências:}

Bannwart, C. J. (2012). "Teoria crítica da sociedade e evolução social”. In: Nobre, M., Repa, L. (Orgs.) Habermas e a reconstrução. Sobre a categoria central da Teoria Crítica habermasiana. Campinas: Papirus.

Celikates, R. (2009). Kritik als soziale Praxis: Gesellschaftliches Selbstverständigung und Kritische Theorie. Frankfurt am Main: Campus Verlag.

- (2012). O não-reconhecimento sistemático e a prática da crítica: Bourdieu, Boltanski e o papel da teoria crítica. Novos Estudos Cebrap, 93.

Habermas, J. (1976). Zur Rekonstruktion des Historischen Materialismus. Frankfurt am Main: Suhrkamp.

. (1984). Vorstudien und Ergänzungen zur Theorie des kommunikativen

Handelns. Frankfurt am Main: Suhrkamp.

. (1987). Theorie des kommunikativen Handelns, vol.I e II. Frankfurt am Main: Suhrkamp.

- (1989). Consciência moral e agir comunicativo. Tradução de Guido de Almeida. Rio de Janeiro: Tempo Brasileiro. - (1992). Faktizität und Geltung. Frankfurt am Main: Suhrkamp. (2014). Conhecimento e interesse. Tradução de Luiz Repa. São Paulo:

UNESP.

Hegel, G. W. F. (2008). Fenomenologia do espírito. Petrópolis: Vozes.

Honneth, A. (2007). "Rekonstruktive Gesellschaftskritik unter genealogischen Vorbehalt". In: Pathologien der Vernunft: Geschichte und Gegenwart der Kritischen Theorie. Frankfurt am Main: Suhrkamp.

. (2010). “Philosophie als Sozialforschung. Zur Gerechtigkeit von David Miller”. In: Das Ich im Wir. Frankfurt am Main: Suhrkamp.

. (2011). Das Recht der Freiheit. Berlin: Suhrkamp.

Horkheimer, M. (1975). “Teoria Tradicional e Teoria Crítica”. In: Benjamin, W. et alli. Textos escolhidos. São Paulo: Abril Cultural.

Iser, M. (2008). Empörung und Fortschritt: Grundlageneiner kritischen Theorie der Gesellschaft. Frankfurt am Main: Campus. (2009). “Rationale Rekonstruktion”. In: Brunkhorst, H., Kreide, R., 
Reconstrução e crítica imanente: Rahel Jaeggi e a recusa do método reconstrutivo...

Lafont, C. Habermas-Handbuch. Stuttgart: Metzler. . (2013). Desrespeito e revolta. Sociologias, 33.

Jaeggi, R. (2008). Repensando a ideologia. Civitas, 8(1).

. (2014). Kritik von Lebensformen. Frankfurt am Main: Suhrkamp.

Kneer, G. (1990). Die Pathologien der Moderne. Zur Zeitdiagnose in der Theorie des kommunikativen Handelns von Jürgen Habermas. Opladen: Westdeutscher.

Nobre, M. (2004). A teoria crítica. Rio de Janeiro: Zahar.

- (2013). "Reconstrução em dois níveis. Um aspecto do modelo crítico de Axel Honneth". In: Melo, R. (Org.). A teoria crítica de Axel Honneth: Reconhecimento, liberdade e justiça. São Paulo: Saraiva.

Nobre, M., Repa, L. (Orgs). (2012). Habermas e a reconstrução. Sobre a categoria central da teoria crítica habermasiana. Campinas: Papirus.

Pedersen, J. (2008). Habermas' method: rational reconstruction. Philosophy of social sciences, 38(4).

Peters, B. (1996). “On reconstructive legal and political theory”. In: Deflem, M. Habermas, Modernity, and Law. Londres: Sage Publications.

Repa, L. (2008). “Reconstrução racional e filosofia da história”. In: Martins, C. A., Poker,J. G. O pensamento de Habermas em questão. Marília: Oficina Universitária Unesp.

- (2008a). A transformação da filosofia em Jürgen Habermas: os papéis de reconstrução, interpretação e crítica, São Paulo: Singular.

Stahl, T. (2013). Habermas and the Project of Immanent Critique. Constellations, 20(4).

Strydom, P. (2011). Contemporary Critical Theory and Methodology. London/New York: Routledge.

Voirol, O. (2012). Teoria Crítica e Pesquisa Social: da dialética à reconstrução. Novos Estudos Cebrap, 93. 